improved method has been developed for the polarimetric determination of starches, and tetrahydrofurfuryl alcohol, easily made from agricultural waste, is a promising permanent type of anti-freeze. A pilot plant was constructed for separating starch and gluten from wheat, based on processes developed in the laboratory, and the expansion of the work on industrial utilization of agricultural wastes and surpluses included the building of a new laboratory. Methods for the extraction of rubber from native and introduced plants continued to receive attention, and the rubber pilot plant was adapted to include solvent-extraction methods. Work on 'tropicalization' assumed major proportions during the year and much Service equipment was placed under test. Copper dimethylglyoximate and other chemical treatments gave promising results for rot-proofing fabrics, especially canvas. In the food field, the work on dried eggs was expanded to include dried egg and sugar mixtures, a product which has shown distinct promise. Work on liquid and shell eggs was renewed, with the emphasis on methods extending their storage life. Co-operative studies with the Ontario Research Foundation and the Associate Committee on Grain Research were continued on processing and treating domestic oils for food. An investigation was initiated on the treatment of butter to improve its stability for use by the Services under tropical conditions.

The various sections of the Division of Chemistry also continued to operate almost exclusively on war problems. Continued co-operation with the Directorate of Chemical Warfare and Smoke included studies to improve the pilot plant yields of organic chemicals and syntheses of new toxic materials, while a small group was engaged on fundamental studies of longrange interest to synthetic rubber manufacture. The design of a pilot plant for ethylene oxide was completed and erection begun. Particular attention was paid to catalysts used in the conversion of ethylene to ethylene oxide. In the Plasties and Colloid Section the chief projects related to the study of density-temperature relations of some plastic materials and the physical properties of plastic and plasticizer combinations. The Plastics Testing Laboratory carried out investigations on waterproof maps, testing of safety goggles, the treatment of leather components for use in the tropies, the improvement of sole leather by impregnation with resins and the examination of periscope prisms to determine the reason for bubble formation in the plastic laminating layer. The Textile Section continued its investigations with special attention to rot-proofing technique. Work on protective clothing for the Air Force was a major project; attention was also given to wear resistance and shrinkage of Service socks. At the request of the Army medical authorities, the oiling of blankets was investigated as a method of preventing transfer of infection in hospitals. The Rubber Laboratory again gave special attention to synthetic rubber compounding, and the scarcity of carbon black required work to determine the effect of reducing the proportion in such materials as footwear. Work was also done on non-skid deck covering. In addition to the problems on the tropicalization of vehicles, packaging of metallic parts, etc., the Corrosion Laboratory carried out long-term investigations of sea-water corrosion of alloys and protective coatings, the study of corrosion inhibitors in tap water and in anti-freezes, the testing of rust-preventing oils and preliminary work on the possible cathodic protection of ships.
The Division of Mechanical Engineering devoted almost its full effort to war work for the Armed Services and the Department of Munitions and Supply. The Hydraulic Laboratory and an addition to the Gasolene and Oil Laboratory were completed and occupied. Fundamental research on the aerodynamic balancing of aircraft controls was extended. Special attention was given to the design and construction of artificial limbs in moulded plywood and moulded synthetic resin materials, and many tests were performed on synthetic resin adhesives with particular reference to the technique of metal bonding.

In the Division of Physics and Electrical Engineering the work was largely in the field of marine physics. In the Acoustics Laboratory three major antisubmarine projects were completed. The main effort of the Optics Laboratory was devoted to research in aerial photography; this work was sponsored by the Canadian Photographic Research Committee. Some thirty-five reports were issued but the circulation list was restricted by security regulations. It can be expected that a new basis for the design of photographic objectives will be developed and photographic lenses will have a greatly improved performance. Much work has been done on night photography for reconnaissance purposes.

In addition to reports on literature searches, the Research Plans and Publications Section made nearly three times as many translations as in the preceding year. During the year, eighty-eight papers were added to the Council's list of publications, which has now attained such proportions that it has been decided to re-issue the list to include author and subject indexes as well as the numerical chronological list of titles. Among the reports issued during the year may be mentioned abstracts on fungi and bacteria affecting various materials, storage of coal and a revised and enlarged edition of abstracts on penicillin and other antibiotic substances, as well as abstracts on the utilization of sawdust.

\section{CONTEMPORARY CULTURE OF THE CAHOHA INDIANS}

7 HE Cáhifa Joftians of western Mexico consist of two survithng groups, the Yaqui and the Mayo. As a resul of his visits to them, Ralph $\mathrm{L}$. Beals has already published an account of what can be gleaned about their aboriginal culture (Ibero-Americana, No. 19 Cllif. Univ. Press, 1943). He now shows (Bull. 142, Bur. Amer. Ethn., Smithsonian Instit., 1945) that their modern culture is a vigorous hybrid, which differs from those of the Indians of the United States in that it is holding its own with that of the whites, though it continually absorbs elements from it. It is by no means sure, as the author points out, that the Indian elements in Mexican culture will be altogether lost in the final synthesis.

This useful account sets out to deal particularly with the ethnography rather than the social anthropology of the Cáhita; nevertheless it contains much information about the latter aspect. There is an interesting summary of the material culture, but much of the book is taken up with accounts of the religious observances. Superficially these appear to centre largely around the Christian Church and calendar, but they contain so many aboriginal elements and introduce the Catholic priest so seldom, 
that they constitute a hybrid which is almost wholly aboriginal in spirit. More specifically aboriginal are certain features which they call the "Religion of the Woods".

Not the least interesting part of the work is the account of how the Yaqui and the Mayo, though their cultures are almost identical in content, react very differently to contact with the Mexicans. The Mayo seems to preserve his way of life by passive resistance, and his attitude is graphically described by the Spanish expression 'muy cerrado' (very shut), in which he resembles many Andean tribes. The Yaqui, on the other hand, is, and has been throughout his history, a fighter, and he preserves his culture by his aggressiveness. The explanation of this deep psychological difference between two closely related groups is one of the principal problems in connexion with these Indians which still await solution.

G. H. S. BushNelt

\section{WOOL TEXTILE RESEARCH IN AUSTRALIA}

\footnotetext{
$\mathrm{T}$
} HE Austelian Council for Scientific and Industrigh Research is to embark on an extensive programme of research on wool production and manufacture. Australia has a sheop population of approxirnately $120,000,000$, from which is derived the most valuable item of her export trade. To aid this/valuable industry the Federal Parliament has recently enacted the Wool Use Promotion Act (1945) and the Wool Tax Act (1936/45) (see Nature, 157, $71 ; 1946)$. The latter of these legislative measures provides for the collection of $2 s$. per bale on all wool produced. This will bring in an annual income of about $£ 300,000$, and this sum is to form the Wool Use Promotion Fund, which is to be administered by the Wool Board, newly constituted under the Wool Use Promotion Act, "to make arrangements with persons, authorities and organizations in Australia and in other countries for joint measures of publicity or other means for the promotion of the use of wool".

The Wool Use Promotion Act empowers the Federal Treasury to create from the consolidated revenue the Wool Research Trust Account of an amount equal to the Wool Use Promotion Fund. These moneys are to be used mainly by the Council for Scientific and Industrial Research. The Council is thus iassured of an annual income accumulating from year to year of approximately $£ 300,000$ with which to plan its research programme.

Approximately half of this money will be devoted to a considerable expansion of the work of the existing laboratories of the Council which have, for some years, been studying the health and nutrition of the sheep and for the initiation of new work on genetics and physiology. Equal importance, however, will be given to research on wool as a textile, for although only $12 \frac{1}{2}$ per cent of Australian wool is processed in the Commonwealth, it is considered to be in the interests of Australia to have the results of textile research applied outside as well as within the Commonwealth.

Textile research is a field into which the Council for Scientific and Industrial Research has not previously entered ; in fact, little research of this type has been undertaken in Australia either in the universities or elsewhere. The Federal Government has, for some years, made an annual contribution to the Wool Industries Research Association in the United Kingdom, and this support will continue to be given. Recently, four men eminent in the field of textile research were invited to Australia to advise the Council for Scientific and Industrial Research on the initial planning of its researches in this field. These were Prof. J. B. Speakman, professor of textile technology of the University of Leeds; Mr. B. H. Wilsdon, director of the Wool Industries Research Association, Leeds; Dr. A. C. Goodings, director of textile research, Ontario Research Foundation, Canada; Dr. F. T. Peirce, formerly of the Shirley Institute, British Cotton Industries Research Association, now director of research, North Carolina State College of Agriculture and Engineering, University of North Carolina, Raleigh, N.C.

It has now been decĩded to form a Division of Wool Textile Research within the Council for Scientific and Industrial Research. This division will have several sectional laboratories devoted to the various aspects of the problem. Although it is the intention to appoint senior scientific men with the required qualifications to take charge of the various sections of the work, the whole endeavour will be co-ordinated under a chief of the Division, in line with the normal administrative arrangements of the Council. The chief will be responsible to the Executive Committee of the Council for the planning of all aspects of the research programme, and the ultimate success of the work will very largely depend on his initiative and ability:

Each of the advisers has emphasized the need for basic research, both in the field of protein science and in applied science, in which the more fundamental knowledge can be interpreted in terms of the manufacturing processes of the industry. If this work is to prosper, the early years must of necessity be devoted to the building up of a competent scientific team in which particular attention must be paid to the more fundamental sciences which are the basis of the textile industry.

\section{FISH MORTALITY DUE TO A BROWN FLAGELLATE}

$\Delta \mathrm{N}$ extensive mortulity of fishes in two brackish. A wate lakes, Jetting Nor and Selsø Sø in the Lesser Bell regf of Denmark, has been found by C. V. Ottenstrem and E. Steemann Nielsen (Rep. Danisl/Biol. Sta., 44 ; 1939) to be associated with a trailitory dominance in the plankton of the brown flagellate Prymnesium parvum Carter, 1938. This cryptomonad has been found before in Europe, always in brackish waters, and in Holland it was also implicated in large-scale destruction of fishes.

Ketting Nor was studied in 1938, immediately after the catastrophe, and again a year later when conditions were returning to normal. A similar crisis was investigated in Selsø $\mathrm{S} ø$ in 1939. It was thought that one of the contributory causes was the increased salinity due to the fjord water entering around the lock-gates, which were imperfectly fitting in both lakes. In Ketting Nor it is probable that this accounted for a reduction in the rate of growth of the plants (the reed crop dropping to half normal in 1938), particularly of the submerged Characeæ which harbour a rich fauna. 